\title{
REVIEWS
}

\section{Photobiomodulation of mineralisation in mesenchymal stem cells}

\author{
Sherif A. Mohamad ${ }^{1}$ (1) $\cdot$ Michael R. Milward ${ }^{1} \cdot$ Mohammed A. Hadis $^{1} \cdot$ Sarah A. Kuehne $^{1,2} \cdot$ Paul R. Cooper $^{3}$
}

Received: 17 December 2020 / Accepted: 22 April 2021 / Published online: 4 May 2021

(c) The Author(s) 2021

\begin{abstract}
Mesenchymal stem cells (MSCs) and photobiomodulation (PBM) both offer significant therapeutic potential in regenerative medicine. MSCs have the ability to self-renew and differentiate; giving rise to multiple cellular and tissue lineages that are utilised in repair and regeneration of damaged tissues. PBM utilises light energy delivered at a range of wavelengths to promote wound healing. The positive effects of light on MSC proliferation are well documented; and recently, several studies have determined the outcomes of PBM on mineralised tissue differentiation in MSC populations. As PBM effects are biphasic, it is important to understand the underlying cellular regulatory mechanisms, as well as, provide accurate details of the irradiation conditions, to optimise and standardise outcomes. This review article focuses on the use of red, near-infra-red (R/NIR) and blue wavelengths to promote the mineralisation potential of MSCs; and also reports on the possible molecular mechanisms which underpin transduction of these effects. A variety of potential photon absorbers have been identified which are reported to mediate the signalling mechanisms, including respiratory chain enzymes, flavins, and cryptochromes. Studies report that R/NIR and blue light stimulate MSC differentiation by enhancing respiratory chain activity and increasing reactive oxygen species levels; however, currently, there are considerable variations between irradiation parameters reported. We conclude that due to its non-invasive properties, PBM may, following optimisation, provide an efficient therapeutic approach to clinically support MSC-mediated hard tissue repair. However, to optimise application, further studies are required to identify appropriate light delivery parameters, as well as elucidate the photo-signalling mechanisms involved.
\end{abstract}

Keywords Odontoblast · Bone · Tooth · Osteogenesis · Odontogenesis · Osteoblast

\section{Introduction}

Repair of hard tissue following trauma or disease remains an essential therapeutic goal in rehabilitating patients back to function. Many orthopaedic patients face the challenge of delayed bone healing resulting in prolonged convalescence and the additional burden on healthcare systems. In oral disease, there is a need to promote hard tissue repair in patients suffering from diseases, such as periodontitis and caries, as

Sherif A. Mohamad

SMA857@bham.ac.uk

1 Institute of Clinical Sciences, School of Dentistry, University of Birmingham, 5 Mill Pool Way, Edgbaston, Birmingham B5 7EG, UK

2 Institute of Microbiology and Infection, University of Birmingham, Edgbaston, Birmingham B15 2TT, UK

3 Department of Oral Sciences, Faculty of Dentistry, Sir John Walsh Research Institute, University of Otago, PO Box 56, Dunedin 9054, New Zealand well as following tooth extraction [1-3]. Regenerative therapies which utilise mesenchymal stem cells (MSCs) provide a promising therapeutic approach. MSCs can be harvested from many bodily sites, including bone marrow, adipose tissue, umbilical cord, and the dental pulp. These cells are multi-potent, can self-renew, and are capable of differentiating into mineralised tissue lineages to generate osteoblasts and odontoblast-like cells [4-6]. MSCs can proliferate to enable repopulation of the injury site, as well as being able to promote revascularization, innervation, and modulation of immune responses [7, 8]. Photobiomodulation (PBM) or low-level light therapy (LLLT) utilises light at relatively low power; inducing tissue regeneration, as well as, modulating pain and inflammation [9].

Radiant exposure $\left(\mathrm{J} / \mathrm{cm}^{2}\right)$ is dependent upon both, the irradiance $\left(\mathrm{mW} / \mathrm{cm}^{2}\right)$ and, irradiation time in seconds (s). The irradiance values vary according to the light source's output power, distance to target, and spot size [9]. As for pulsed light, irradiance is also affected by the duty cycle and pulse frequency [10]. PBM is known to exhibit a biphasic 
dose-dependent response and bio-stimulation for each specific cell type or tissue occurs only through a therapeutic window of doses [11]. This defies the reciprocity laws; meaning that if the radiant exposure was kept constant while changing the irradiance and irradiation time, the end results will not be similar $[12,13]$. Consequently, the Arndt-Schulz law has provided an appropriate model to describe the dosedependent effects of PBM. This law states that insufficient stimuli exert no effects, relatively low stimuli exert a stimulatory effects, while higher stimulus causes inhibition. If the radiant exposure is too high (higher irradiance or longer exposure times) or too low; no response or an inhibitory effect could occur. Furthermore, other irradiation parameters can also affect cellular responses, such as the mode of operation, i.e., continuous wave or pulsed, and the wavelength applied. It is important to understand that the energy of photons is dependent on the wavelength of light used, e.g., blue light photons contain more energy per photon, compared with red light. The absorption of blue light in most tissues is higher, because fundamental tissue chromophores have dominating absorption bands in the blue light region. It is therefore important to fully understand the light irradiation parameters applied to optimise the therapeutic outcomes and avoid unwanted side effects. Benefits of PBM can include regulation of the activity of growth factors, cytokines, and inflammatory mediators $[9,12,14]$.

Several investigations have reported that red $(620-660 \mathrm{~nm})$ and near-infra-red (800-980 nm) (R/NIR) light can enhance MSC proliferation [15, 16]. Other studies have now also reported on osteo- and odonto-genic differentiation outcomes following irradiation by R/NIR light [10, 17-22]. Blue light (400-500 nm) has recently been shown capable of up-regulating the osteogenic potential of MSCs [23-27]. Even though the PBM mechanisms are not fully elucidated [9], the most widely accepted theory for the R/NIR PBM effects is in response to light absorption by cytochrome $c$ oxidase (COX); which subsequently leads to stimulation of the respiratory chain and associated adenosine tri-phosphate (ATP) production [28]. The mode of action of blue light is, however, reportedly primarily mediated through a relatively small increase in reactive oxygen species (ROS) levels; after the light has been absorbed by cellular flavins [29, 30]. ROS are also secondarily generated as a result of stimulating the respiratory chain by R/ NIR light [31]. Notably, the redox state of MSCs is reported as being an important modulator of both proliferation and mineralisation processes [32, 33].

A combined application of PBM and MSCs therefore offers a prospective therapeutic modality for the promotion of hard tissue repair and regeneration. However, to optimise its clinical use, the mechanisms governing their interactions need to be better understood. Indeed, it will be important to determine how different wavelengths interact with different chromophores; and subsequently determine how ROS responses may be generated resulting in the downstream molecular and cellular events. Furthermore, the accurate characterisation and reporting of irradiation parameters applied is also critical to enable optimisation of therapeutic light delivery. This review article explores potential PBM mechanisms involved in mediating MSC responses and reports on in vitro studies investigating blue and R/NIR light effects on cellular mineralisation capacity. Bibliographical searches were performed using ScienceDirect and PubMed. To identify in vitro studies reporting on the effects of blue and R/NIR light on the mineralisation potential of MSCs, the keywords used included combinations of: 'PBM', 'LLLT', 'phototherapy', 'osteogenic/odonto-genic differentiation', and 'MSCs'. Studies which only investigated light effects on proliferation were excluded; while those investigating osteo/ odontogenesis were included. Subsequently, a methodological quality check was performed; in which studies lacking essential dosimetry and light characterisation parameters were not included. Studies which were included contained sufficient information for a radiant exposure to be calculated, and hence, the irradiation part of the experiment is repeatable.

\section{PBM signal transduction in the red/ near-infra-red spectrum}

Following the absorption of photons, the resulting excited molecule exerts biologic effects by modulating intracellular metabolic pathways. Depending on the radiant exposure, light absorption can either cause increases in ATP and cyclic adenosine monophosphate (cAMP) levels resulting in downstream bio-stimulation, or destruction of cytochromes, which results in inhibitory effects. Both processes are proposed to take place within mitochondria [34]. The primary photoreceptor or chromophore which reportedly absorbs light photons is COX which is a terminal enzyme in the respiratory chain and plays a major regulatory role in the process of oxidative phosphorylation. The enzyme consists of two heme, two copper, one magnesium, and one zinc site. COX transfers electrons from cytochrome $c$ to molecular oxygen, and this leads to the oxidation of ferrocytochrome $c$ and the reduction of a di-oxygen molecule; inducing proton pumps from the mitochondria to the cytosol. Ultimately, the energy produced from this redox process leads to the generation of ATP [31, 35].

Karu et al. established a direct link between optical radiation, in the ultraviolet and infra-red spectrum $(300-900 \mathrm{~nm})$, and stimulation of both DNA and RNA synthesis in HeLa cells. DNA synthesis stimulation peaks were recorded at wavelengths of $400,630,680$, and $760 \mathrm{~nm}$, while those for RNA synthesis were detected at 400,615, 680, 780, and $820 \mathrm{~nm}$. 
Data indicated that light was not absorbed directly by the nucleic acids but that light regulated their synthesis indirectly [36]. To elucidate the photo-absorber, they used a light source of a narrower spectrum (580-860 nm). Four peaks for DNA and RNA synthesis were identified; two within the red spectrum (613-623 nm and 667-683 nm), and two within the NIR spectrum (750-772 $\mathrm{nm}$ and $812-846 \mathrm{~nm}$ ). These results supported the hypothesis that COX was the main endogenous chromophore; as the $613-623 \mathrm{~nm}$ absorbance wavelength was within the same absorbance maxima for reduced COX, while the $667-683 \mathrm{~nm}$ wavelength also conformed to one of the COX intermediates, compound A (fluoromethyl-2,2-difluoro-1-trifluoromethyl vinyl ether). Moreover, peaks recorded at 750-772 nm correlated with the absorption coefficient of mitochondria; and the 812-846 $\mathrm{nm}$ wavelengths corresponded with oxidized COX [28]. Further studies demonstrated that cell exposure to nitric oxide (NO), a COX inhibitor, eliminated the bio-stimulatory effects of R/NIR light and this was also accompanied by significant changes in COX absorption. NO is known to compete with oxygen for binding at the COX copper $(\mathrm{CuB})$ nuclear center. Notably, light reportedly dissociates the binding of $\mathrm{NO}$ from $\mathrm{COX}$, which can then enable cellular respiration and oxygenation by reversing the hypoxic conditions in stressed cells. In turn, this increases electron transfer and ATP production, subsequently inducing transcription factors which can enhance cellular migration, proliferation, and differentiation responses [37-39]. Further studies by WongRiley et al. investigated the effects of five different irradiation wavelengths $(670,728,730,830$, and $880 \mathrm{~nm})$ following pre-treatment of neuronal cells with potassium cyanide; an inhibitor of COX that also binds to the $\mathrm{CuB}$ nuclear center. The delivered light demonstrated an ability to restore COX activity and ATP levels; with outcomes being dose-dependently related to the potassium cyanide levels applied. The most efficient wavelengths applied were 630 and $830 \mathrm{~nm}$, and these correlated with the absorbance spectrum of oxidised COX. As potassium cyanide could have been bound to other proteins within the cell, such as catalase, NO synthase, cytochrome $\mathrm{b}$, and cytochrome $\mathrm{c}$; these data therefore did not rule these molecules out as prospective chromophores [40]. Interestingly, it has been reported that PBM effects in the R/NIR spectrum also occur due to the simultaneous production of relatively low amounts of ROS; alongside increases in ATP production. This takes place due to the shift in the cellular redox state towards higher oxidation levels, by simultaneously increasing mitochondrial ROS and decreasing cytosolic ROS [10, 31] (see Fig. 1).

\section{Blue light PBM signal transduction}

Several mechanisms have been reported to mediate blue light absorption and activation of downstream signalling pathways. Indeed, it is possible that more than one pathway is activated by blue light simultaneously or that sequential signalling may occur. Furthermore, differences in cell type, metabolic state, and chromophore levels likely play a pivotal role in determining the response detected. Early hypotheses have proposed that shorter wavelengths of blue light $(400 \mathrm{~nm})$ were absorbed by porphyrins, leading to the release of ROS; mainly in the form of singlet oxygen. Cellular mitosis is subsequently triggered via stimulation of the respiratory chain and calcium influx into the cytoplasm. Notably, however, at higher radiant exposure, molecular and cellular damaging effects could also occur due to the high reactivity of the singlet oxygen generated [36, 41].

Due to their key roles in the respiratory process, redox chain molecules are candidates for blue light signal transduction. Indeed, the flavin constituents have been proposed as chromophores; and this includes molecules such as Nicotinamide adenine dinucleotide phosphate (NADPH) dehydrogenase [35] and NAPDH oxidase. Studies have shown that hydroxyl radicals were induced in sperm cells following irradiation using blue spectrum light. Results suggested that the endogenous photosensitizer was flavin-bound; and was prevalent in the cytosol [29]. Other studies have detected increased mitochondrial ROS production after irradiating sperm cells, fibroblasts, cardiac, and skeletal muscle cells. The addition of an extracellular scavenger led to a reduction in hydroxyl radicals; findings which supported the hypothesis that ROS is produced at the cell membrane level potentially due to the sensitization of NADPH oxidase [42].

Intracellular ROS induced by light are mainly superoxide anions, hydrogen peroxide $\left(\mathrm{H}_{2} \mathrm{O}_{2}\right)$, and hydroxyl radicals $[43,44]$, and these can be formed due to type I or type II reactions. In type I reactions, electron transfer from the excited sensitizer to oxygen produces a superoxide anion and $\mathrm{H}_{2} \mathrm{O}_{2}$, which in turn is transformed to hydroxyl radicals through Harber-Weiss or Fenton reactions. A type II reaction results in the production of singlet oxygen. Interestingly, it has been hypothesised that the type I reaction conforms closely with the ascending part of the Arndt-Schultz curve when light irradiation, up to a certain radiant exposure, results in the bio-stimulation of ROS. Longer periods of irradiation, or higher radiant exposure, correlates with the descending part of the curve; due to the elevated ROS production and activation of the cellular scavenging system which causes an imbalance in the redox state of the cell. A concomitant rise in intracellular 


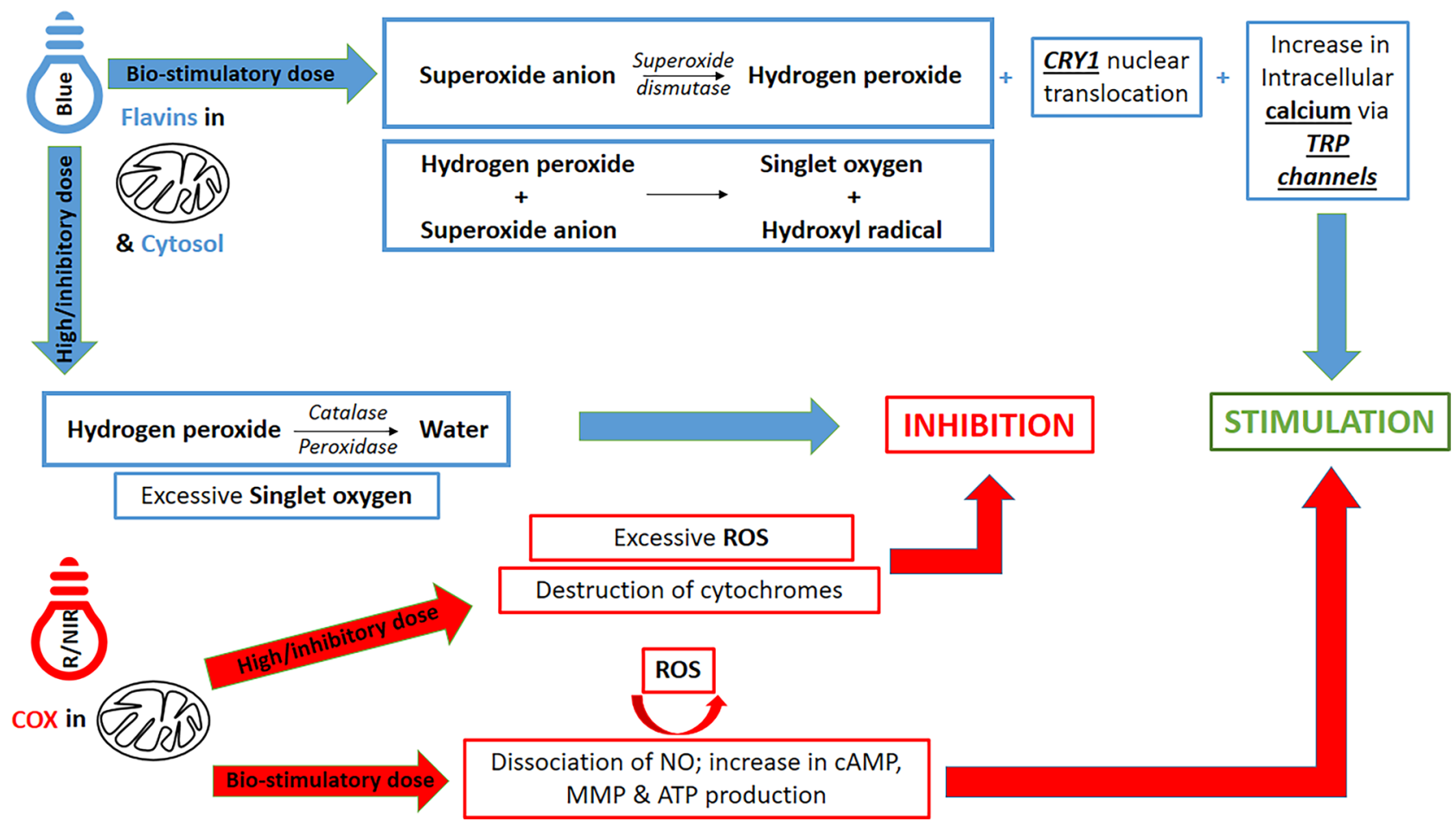

Fig. 1 Schematic diagram showing blue and red/near infra-red (R/ NIR) light potential bio-modulatory mechanisms. At the stimulatory dose (i.e., radiant exposure), blue light (absorbed by flavins in both mitochondria and cytosol) induces the production of stimulatory levels of hydrogen peroxide, causing an elevation in intracellular calcium levels through transient receptor potential (TRP) channels. These effects are accompanied by decreased crytochrome- 1 (CRY1) activity. R/NIR light dissociates nitric oxide (NO) bound to cytochrome $c$ oxidase (COX) inside the mitochondria, enhancing cyclic adenosine monophosphate (cAMP), mitochondrial membrane potential (MMP), and adenosine tri-phosphate (ATP) production. At higher doses, blue light can cause inhibition due to the up-regulation of the scavenging system (catalase/peroxidase). Inhibitory effects of a higher dose of R/NIR light can occur due to the destruction of cytochromes. Nevertheless, both spectral ranges can cause inhibition due to the excessive production of ROS calcium levels accompanies the ROS increase. Thus, it has been proposed that a transient increase in calcium, induced by $\mathrm{H}_{2} \mathrm{O}_{2}$, may be responsible for the bio-stimulatory effects, while more rapid increases in calcium cause inhibitory effects which are consistent with the descending part of the Arndt-Schultz curve [30] (see Fig. 1).

In addition to NADPH-dependent enzymes, flavin adenine dinucleotide (FAD) containing cryptochromes (CRY1 and CRY2) have also been proposed as blue light absorbers in humans [45]. CRY proteins are circadian rhythm regulators which modulate cell and tissue haemostasis $[46,47]$ (see Fig. 1). CRY1 and CRY2 specifically act as negative feedback regulators of the circadian clock and decreased levels of these molecules can increase bone formation. Increased ROS can also reset the cellular circadian clock as well as optimising cellular survival mechanisms [48-50].

\section{Intracellular ROS levels regulate MSC haemostasis and fate}

As has previously been highlighted, ROS can be generated within mitochondria during electron transport by a range of enzymes, including NADPH oxidase, NO synthase, mono-amide oxidase, heme oxygenase, lipoxygenase, myeloperoxidase, cyclooxygenase, and cytochrome P450 [51-53]. Other cellular locations for ROS generation include the cytosol (NO synthase/lipoxygenase), plasma membrane (NADPH oxidase/lipoxygenase) [54-57], endoplasmic reticulum (NAPDH oxidase) [58, 59], and peroxisomes [60]. In MSCs, ROS play a pivotal role in determining cell fate as well as regulation of their selfrenewal. Notably, several studies have reported that the 
application of exogenous ROS can stimulate mineralising marker expression in both dental pulp stem cells (DPSCs) [61] and adipose tissue-derived MSCs (ADMSCs) [62].

During homeostasis, ROS levels are regulated by a range of antioxidant/scavenging enzymes including catalases, superoxide dismutase, glutathione reductase, and glutathione peroxidase. If ROS levels reach certain thresholds; beyond the point which the scavenging enzymes can modulate, cellular injury occurs due to oxidation of several molecules, including nucleotides, lipids, and proteins [63]. Undifferentiated MSCs contain relatively low levels of ROS, and express high levels of antioxidant enzymes; however, the opposite state exists for MSCs during their proliferation and differentiation phases [32, 33, 64, 65]. During MSC differentiation, the main sources of ROS are complex I (NADH coenzyme Q oxidoreductase), complex III (ubiquinol cytochrome $c$ oxidoreductase), and NADPH oxidase [66]. Similar to other cellular processes, excessive levels of ROS inhibit both proliferation and osteogenic differentiation [67].

Further evidence highlighting the role of the redox status in regulating MSC activity is highlighted by the importance of the master regulator of anti-oxidative responsive transcription factor, nuclear factor erythroid related factor-2, in the process. Its knockout increases cellular differentiation processes and bone formation [62]. Combined, these data indicate the fine balance the redox state plays in regulating cellular events and identifies a potential mechanism by which light can indirectly influence MSC fate.

\section{PBM promotes MSC mineralisation processes in vitro}

\subsection{Red light}

Red light (620-660 nm) irradiation has been reported to significantly increase the proliferation of bone marrow MSCs (BMMSCs) [17-19] and periodontal ligament stem cells [20] at radiant exposures of 1,2 , and $4 \mathrm{~J} / \mathrm{cm}^{2}$. Notably, osteogenic differentiation was also promoted after 2 and $4 \mathrm{~J} / \mathrm{cm}^{2}$, as demonstrated by up-regulation of alkaline phosphatase (ALP), osteocalcin (OCN), bone gamma-carboxyglutamic acid-containing protein [17-20], runt-related transcription factor-2 (RUNX2) [18-20], bone morphogenic protein-2 (BMP2) [19, 20], collagen-1 $\alpha$ (Col-I $\alpha)$ [18], and insulin-like growth factor-1 [19]. Importantly, data also demonstrated concomitant increases in mineral deposition [18-20] (see Table 1).

Enhanced bio-stimulatory effects in MSCs have also been observed when cultures were irradiated either once daily $[20,21]$ or every other day $[18,19]$. Higher irradiance values and multiple exposures resulted in enhanced mineralising outcomes compared with single exposure controls [18]. It is notable that PBM effects were inhibited by culture supplementation with SQ22536, an adenylyl cyclase inhibitor; supporting the role of cAMP and respiratory chain signalling in the photo-transduction process [21].

\subsection{NIR irradiation}

NIR diode irradiation ( $810-850 \mathrm{~nm}$ ) was reported to stimulate the proliferation $[10,21]$ and osteo-/odonto-genic potential of BMMSCs [21, 68], ADMSCs [22], DPSCs [10], and stem cells from human exfoliated deciduous teeth [69], at radiant exposures ranging from $77 \mathrm{~mJ} / \mathrm{cm}^{2}$ to $4 \mathrm{~J} / \mathrm{cm}^{2}$. Irradiated cell cultures exhibited higher levels of mineralisation markers, including ALP [10, 21, 22, 69], Col-I $\alpha$, Dentin matrix phosphoprotein-1 (DMP-1), and dentin sialophosphoprotein (DSPP) [69]. At relatively high radiant exposure $\left(64 \mathrm{~J} / \mathrm{cm}^{2}\right)$, diode laser $(808 \mathrm{~nm})$ irradiation also significantly increased mineral deposition in BMMSC cultures via the upregulation of ALP, RUNX2, transforming growth factor-ßeta 1 and Osterix (OSX) [68] (see Table 1).

\subsection{Blue light}

The bio-modulatory effects of blue light have only relatively recently been reported, and there has been considerable diversity in the light sources used, irradiation parameters applied, and outcomes. Yuan et al. reported that blue light (470 nm LED) adversely affected the proliferation and mineralisation potential of BMMSCs at a relatively wide range of radiant exposures from 1 to $72 \mathrm{~J} / \mathrm{cm}^{2}$ [70]. When gingival MSCs were treated with 420-480 $\mathrm{nm}$ LED irradiation at 1, 2 , 4 , or $6 \mathrm{~J} / \mathrm{cm}^{2}$, results indicated a significant reduction in proliferation rates but increases in both ALP levels and calcified nodule formation. The same light source promoted the osteogenic differentiation of stem cells from apical papilla after irradiation at $1,2,3$, and $4 \mathrm{~J} / \mathrm{cm}^{2}$. These effects reportedly occurred due to up-regulation of DSPP, OCN, and DMP-1 [26, 27].

Notably, the increase in calcified nodule formation at 28 days after irradiation was observed in a dose-dependent relationship; suggesting that lower radiant exposures promoted early differentiation, while higher radiant exposures exerted enhanced effects, albeit at a more latent stage [26]. Exposure to $420 \mathrm{~nm}$ LED irradiation at $3 \mathrm{~J} / \mathrm{cm}^{2}$ also increased expression of the mineralising markers RUNX2 and OCN, in ADMSCs at 21 days. These effects were also reportedly regulated by an increase in intracellular calcium signalling [25] (see Table 2).

Continuous wave laser (405 nm) exposure at 9, 18, 27, 36 , and $54 \mathrm{~J} / \mathrm{cm}^{2}$ was shown to enhance osteogenic differentiation in mouse BMMSCs cultures, in a dose-dependent manner. These outcomes were supported by increased ALP and OCN expression (see Table 2). Immuno-staining 


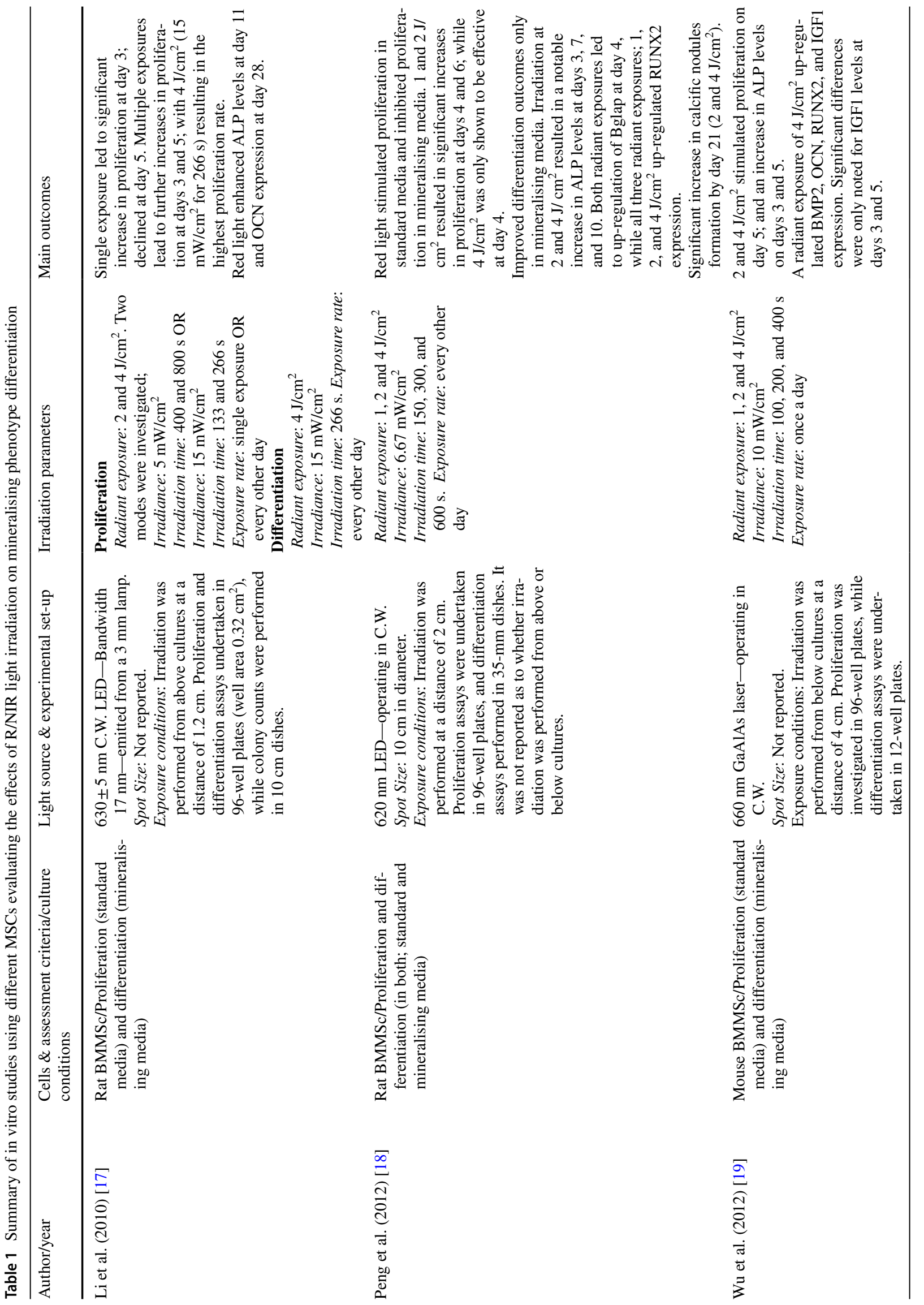




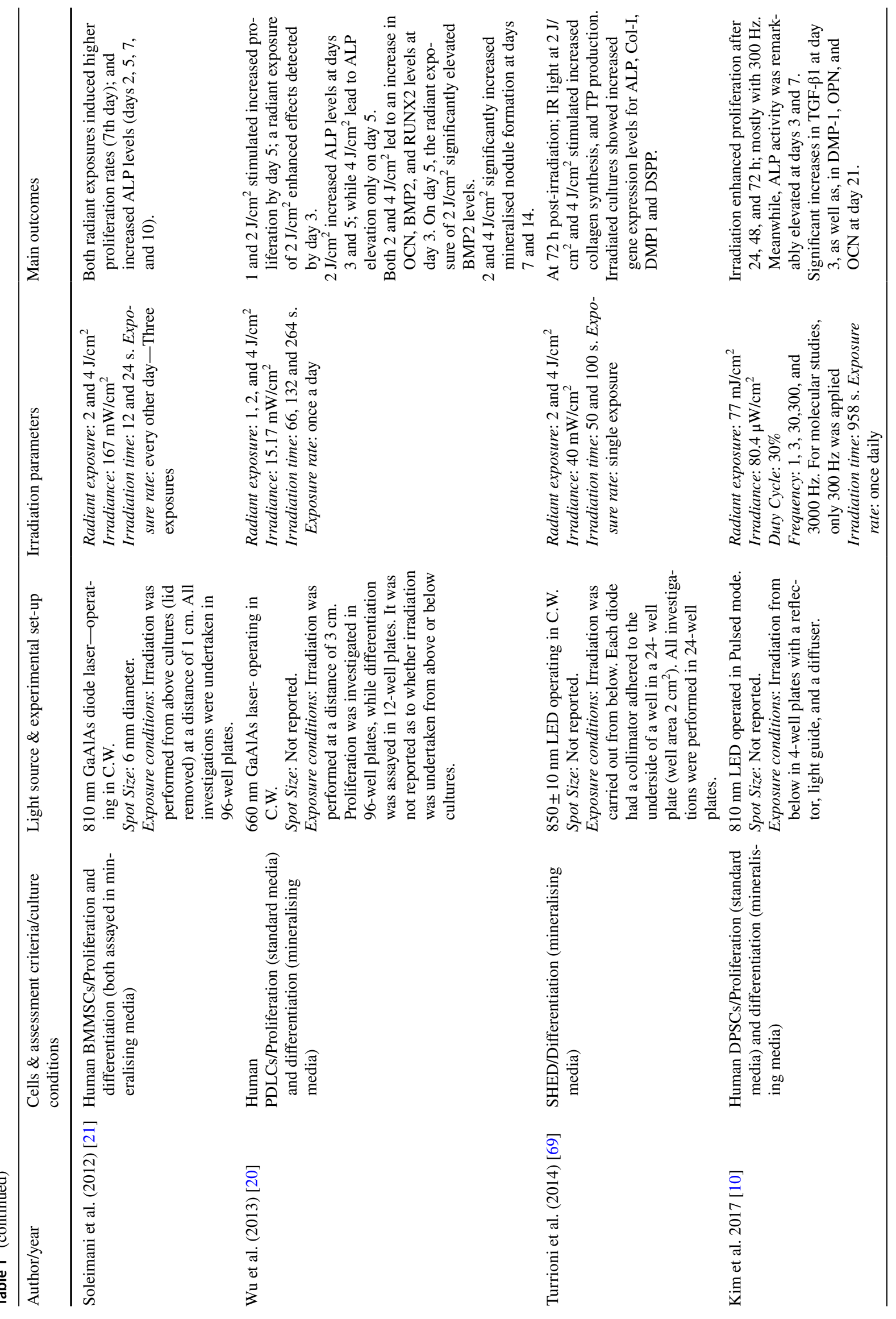




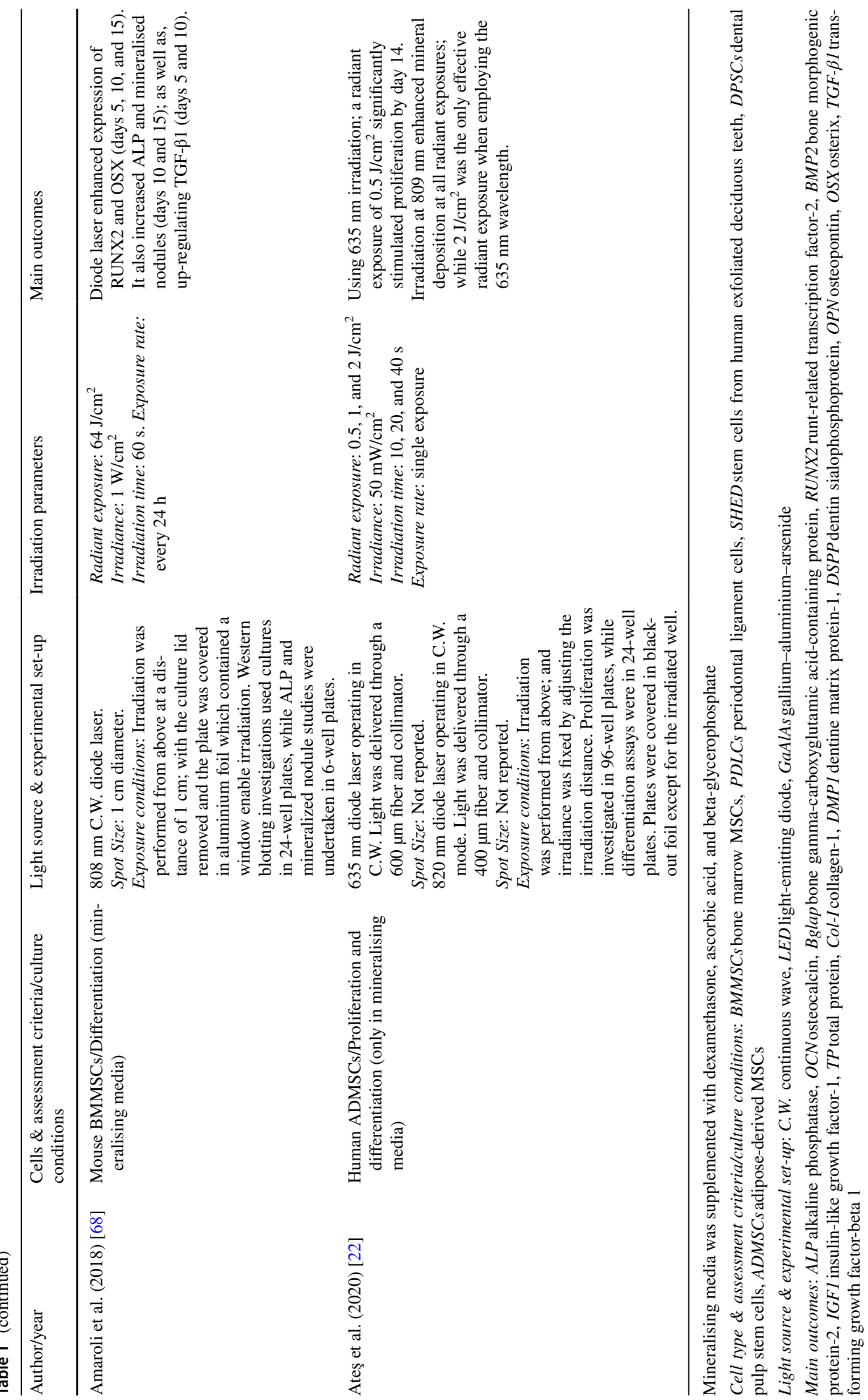




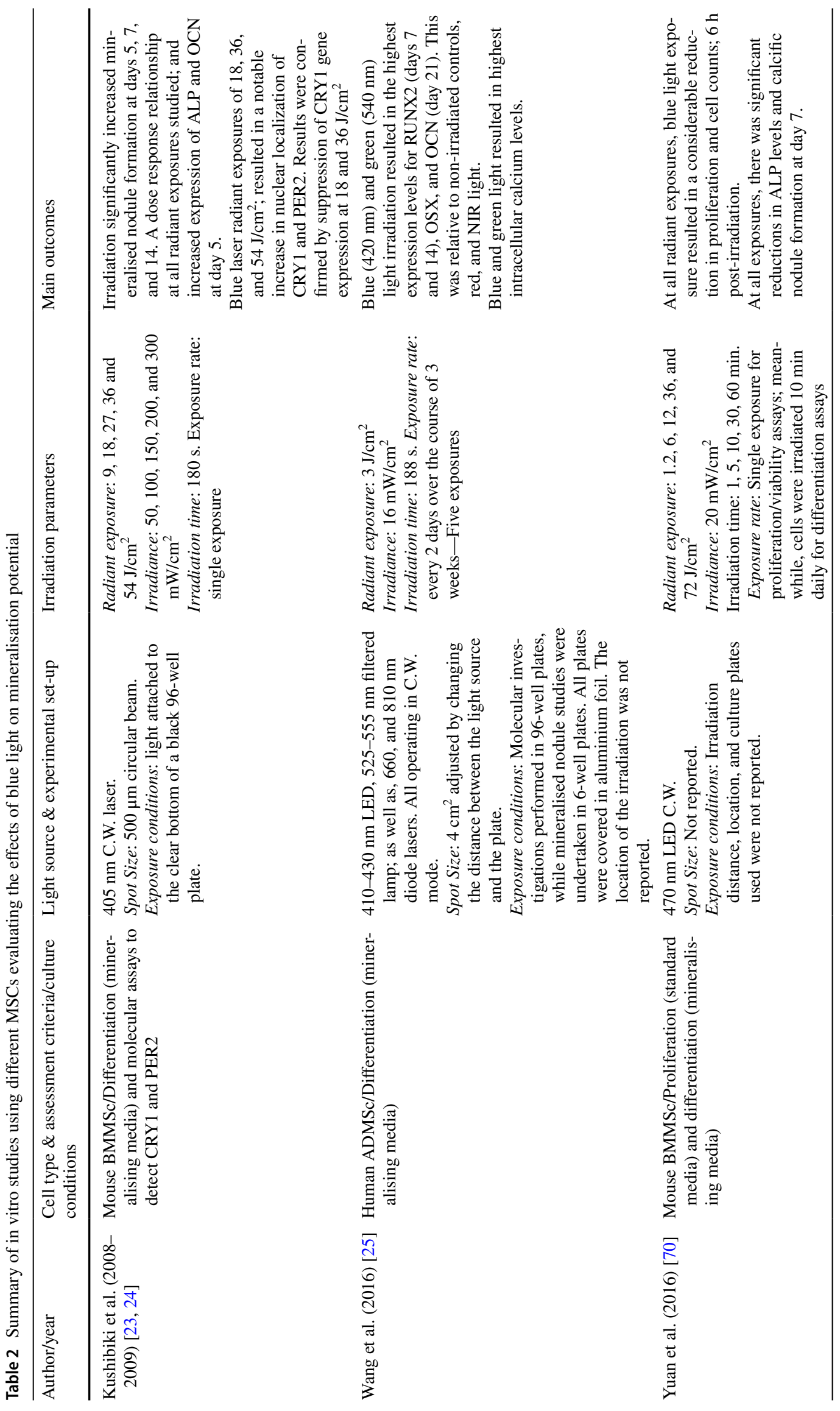




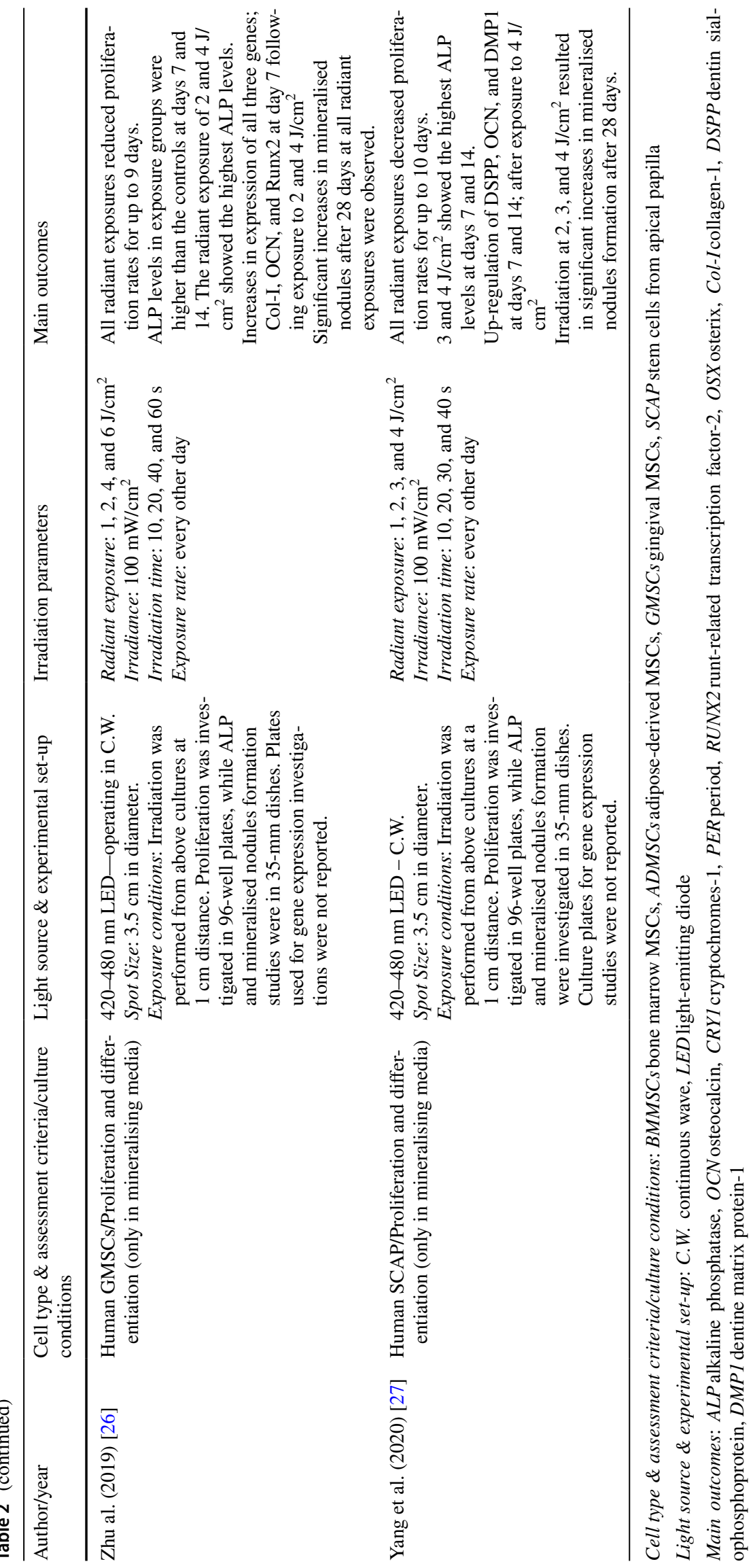


confirmed the nuclear accumulation of the clock proteins, CRY1 and Period-2. CRY1 down-regulation occurred in a dose-dependent manner, at levels above $18 \mathrm{~J} / \mathrm{cm}^{2}$, and the authors proposed that blue light was able to reset the circadian clock in MSCs. Notably, however, 664 and $808 \mathrm{~nm}$ light irradiation did not affect the expression of CRY1 [23, 24].

The application of transient receptor potential channel antagonists, including capsazepine and SKF96365, have been shown to abolish the bio-stimulatory effects of blue light, suggesting involvement of light-gated channels in the PBM mechanism. The original enhancement in mineralisation processes reportedly occurred via an ROS-mediated mechanism, accompanied by an increase in intracellular calcium, which was transduced by light-gated ion channels $[25,29,30]$.

\section{Discussion and Conclusions}

This review has outlined the different PBM mechanisms reported to enhance the mineralisation potential of MSCs, using either blue or R/NIR light. Studies have shown that light in the R/NIR spectrum can have positive bio-stimulatory effects on MSCs in terms of both proliferation and mineralising phenotype differentiation. These effects predominantly occur using both continuous-wave LEDs and lasers at relatively low radiant exposures of up to $4 \mathrm{~J} / \mathrm{cm} 2$ [17-21]. The majority of the studies reporting multiple irradiations did not specify the exact number of treatments applied to the MSCs except for the study by Soleimani et al. [21], which utilised an estimated cumulative radiant exposure of $6-12 \mathrm{~J} / \mathrm{cm}^{2}$. Assuming that in studies where multiple irradiations were applied throughout the full duration of the mineralised nodules formation assay, the cumulative radiant exposure would be in the range of 10-50 J/ $\mathrm{cm}^{2}$ [17-20]. Interestingly, it was also reported that multiple NIR laser irradiations at much higher radiant exposures of $64 \mathrm{~J} / \mathrm{cm}^{2}$ [68] could enhance osteogenic processes.

Relating to the Arndt Schultz model for the biphasic dose-dependent effects, several irradiation parameters trends were observed. With regards to R/NIR light, different combinations of irradiances and irradiation times were used to deliver a range of radiant exposures from 0.5 to $4 \mathrm{~J} / \mathrm{cm}^{2}$. With multiple red light $(620-660 \mathrm{~nm})$ irradiations, 1 and $2 \mathrm{~J} /$ $\mathrm{cm}^{2}$ enhanced proliferation-compared with $4 \mathrm{~J} / \mathrm{cm}^{2}$ - when irradiation was undertaken at 6.67 and $15 \mathrm{~mW} / \mathrm{cm}^{2}$. However, 2 and $4 \mathrm{~J} / \mathrm{cm}^{2}$ resulted in enhanced proliferation-in comparison with $1 \mathrm{~J} / \mathrm{cm}^{2}$ - at $10 \mathrm{~mW} / \mathrm{cm}^{2}$ [18-20]. Moreover, a single exposure of $0.5 \mathrm{~J} / \mathrm{cm}^{2}$ at $50 \mathrm{~mW} / \mathrm{cm}^{2}$ significantly enhanced proliferation compared with 1 and $2 \mathrm{~J} / \mathrm{cm}^{2}$ [22]. Conversely, 2 and $4 \mathrm{~J} / \mathrm{cm}^{2}$ enhanced the mineralisation processes in a dose-dependent manner regardless of the irradiance or irradiation time [17-20, 22]. As for NIR light
(808-850 nm), differentiation was also stimulated in a similar dose-dependent trend using 2 and $4 \mathrm{~J} / \mathrm{cm}^{2}$ when MSCs were irradiated once $\left(40 \mathrm{~mW} / \mathrm{cm}^{2}\right)$ or up to three irradiations $\left(167 \mathrm{~mW} / \mathrm{cm}^{2}\right)[21,69]$. Notably, when employing a single irradiation at $50 \mathrm{~mW} / \mathrm{cm}^{2}, 0.5$ and $2 \mathrm{~J} / \mathrm{cm}^{2}$ resulted in higher mineralised nodules formation compared with $1 \mathrm{~J} / \mathrm{cm}^{2}$ [22]. All these trends were common using both lasers and LEDs, indicating that successful phototherapy approaches depend on the irradiation parameters, rather than the light delivery source [12].

Several studies investigated different irradiation modes to optimise light delivery. $L i$ et al. studied the effects of 2 and $4 \mathrm{~J} / \mathrm{cm}^{2}$ (630 $\mathrm{nm}$ LED)—on BMMSCs-delivered in two modes, $5 \mathrm{~mW} / \mathrm{cm}^{2}$ (400 and $800 \mathrm{~s}$ ) or $15 \mathrm{~mW} / \mathrm{cm}^{2}$ (133 and $266 \mathrm{~s}$ ); they also studied single or multiple irradiations. Their results showed that multiple irradiations at $15 \mathrm{~mW} /$ $\mathrm{cm}^{2}$ for $266 \mathrm{~s}$ resulted in the highest proliferation rates [17]. Moreover, Kim et al. reported that pulsed $810 \mathrm{~nm}$ LED light was more effective in enhancing ALP levels in DPSCs, compared with continuous-wave irradiation. They examined the effects of a range of duty cycles $(0-60 \%)$ at a fixed pulse frequency $(1 \mathrm{~Hz})$, which typically resulted in a range of radiant exposures $\left(0.8-154 \mathrm{~mJ} / \mathrm{cm}^{2}\right)$. The duty cycle indicates the percentage of time the light is on over the entire 'on-off' cycle. A duty cycle of $30 \%$ resulted in the most hyperpolarized cytoplasmic membrane potential. At fixed frequency $(1 \mathrm{~Hz})$ and duty cycle $(30 \%)$, cells exhibited similar ALP levels when irradiated at both $77 \mathrm{~mJ} / \mathrm{cm}^{2}$ and $2.3 \mathrm{~J} / \mathrm{cm}^{2}-$ at variable irradiation times. Additionally, at fixed radiant exposure $\left(77 \mathrm{~mJ} / \mathrm{cm}^{2}\right)$, and duty cycle $(30 \%)$, a frequency of $300 \mathrm{~Hz}$ resulted in highest ALP levels when studying a range of different frequency settings; $1-3000 \mathrm{~Hz}$. These results indicated that the duty cycle and pulse frequency are the main parameters influencing DPSC response, as opposed to the radiant exposure. Nonetheless, the radiant exposure settings applied [10] were much lower compared with other studies investigating the effects of continuous-wave R/NIR light $[17-22,69]$. This violates the Arndt-Schulz law if both continuous and pulsed irradiation are hypothesised to enhance mineralisation relying on the same photo-chemical mechanism.

For blue LED irradiation, induction of MSC osteogenic differentiation and inhibition of proliferation occurred as a result of multiple irradiations at radiant exposures within a range from 1 to $6 \mathrm{~J} / \mathrm{cm}^{2}$, utilising an irradiance of $100 \mathrm{~mW} /$ $\mathrm{cm}^{2}$ (cumulative $10-80 \mathrm{~J} / \mathrm{cm}^{2}$ ) [26, 27]. However, at much lower irradiance $\left(16 \mathrm{~mW} / \mathrm{cm}^{2}\right)$, longer exposure times, and only five irradiations, $3 \mathrm{~J} / \mathrm{cm}^{2}$ (cumulative $15 \mathrm{~J} / \mathrm{cm}^{2}$ ) was required to stimulate MSCs mineralisation [25].

At higher radiant exposures; multiple blue LED irradiations $\left(12 \mathrm{~J} / \mathrm{cm}^{2}\right)$ inhibited osteogenesis [70], while single blue laser irradiation $\left(9-54 \mathrm{~J} / \mathrm{cm}^{2}\right)$ stimulated mineralisation [23, 24]. Compared with LEDs, both blue and NIR 
lasers were shown to enhance MSCs mineralisation only at considerably higher radiant exposure. Further investigation, especially using the higher energy of blue light photons, is required to ensure that irradiation does not lead to injury of local tissues. Intriguingly, enhancement of the mineralisation potential of MSCs using R/NIR light was reported to occur with either fewer treatments at higher irradiance parameters $\left(40-167 \mathrm{~mW} / \mathrm{cm}^{2}\right)$ (shorter exposure times), or increased treatments at lower irradiance $\left(6-15 \mathrm{~mW} / \mathrm{cm}^{2}\right)$ (longer exposure times). However, the converse was the case for blue light irradiation, since MSCs irradiated at 16 $\mathrm{mW} / \mathrm{cm}^{2}$ required only five exposures compared with cultures irradiated at $100 \mathrm{~mW} / \mathrm{cm}^{2}$ every other day. Reciprocity between irradiance and exposure times was evident throughout various R/NIR investigations, which was not reported for blue light studies [17-22, 25-27, 69].

Notably, as is highlighted in Tables 1 and 2, there were variations among the experimental conditions regarding the type of MSCs culture-ware used, location of irradiation source, and irradiation distance. Remarkably, different studies reported using fixed irradiance values, even though irradiation was carried out in different culture dishes within the same study. The use of different size culture-ware will clearly result in the generation of different irradiance at target, different cell densities, and different light-cellular interaction. Despite this, to address this issue, the studies by Ateş et al. [22] and Wang et al. [25] reported adjusting the irradiation distance within the various culture-plate setups to enable maintenance of the same spot size and irradiance. Other differences in experimental set-up were also reported in attempts to maintain homogeneity of delivered light and decrease bleed. For example, in some designs, the cultureware plate lid was removed before covering the entire plate with aluminium foil except for a window to enable the light source to be used to deliver the light from above the culture at a fixed distance [68]. Other designs relied on changeable distance to target while keeping the light spot and aluminium foil window size fixed [25]. While the aluminium foil can cause multiple light reflections and affect the light-cellular interaction, some authors preferred covering the plates with blackout foil or using black-walled well plates [22-24].

Another important variable which should be considered is the potential effect of temperature change following light irradiation. Only the two studies of Li et al. [17] and Turrioni et al. [69] reported measuring thermal affects. In the first study, red LED $(630 \mathrm{~nm})$ irradiation resulted in less than $0.26{ }^{\circ} \mathrm{C}$ temperature increase in the media, while in the latter study, no significant rise in temperature was detected at up to $2 \mathrm{~min}$ of $850 \mathrm{~nm}$ LED irradiation. In vivo, the heat dissipation in cultures depends on their thermal relaxation time, as well as the irradiance, irradiation time, pulse frequency, and pulse duration of the light source [71]. It is also notable that non-irradiated controls in all the experimental designs studied were kept outside the incubator for the same amount of time it took their counterparts to be irradiated. This means that depending on the local temperature, the irradiated samples might experience a rise in temperature below their thermal tolerance, which may not be the case in a clinical setting. While PBM is generally accepted as a non-thermal response [9], the effect of hyperthermia cannot be totally ruled out specially it is known to lead to an increase in mitochondrial ROS production [72]. Notably, hyperthermia is reported to enhance the osteogenic differentiation of BMMSC's via the up-regulation of ALP, OSX, RUNX2, BMP2, and osteopontin. These effects are mediated by the heat shock protein (HSP70), and its knockout alleviated the positive effects of hyperthermia [73-75]. If the phototherapy mechanism involves hyperthermia, this would mean that total energy of all light photons absorbed in different molecules-aside/alongside the chromophore-will dictate the resulting effects. Therefore, generally, this means that blue light — with higher energy per photon [14]—exhibits a greater ability to cause hyperthermia compared with red light with similar number of photons. However, from a photo-chemical prospective, both the wavelength used and the absorption spectrum of the chromophore influence the outcomes [71]; and not the energy per photon. Therefore, with the variations among experimental setups, light sources, cultures dishes, and the lack of any media absorption measurements, hyperthermia cannot be excluded. It also means that the inclusion of appropriate thermal controls should be included in all studies.

Interestingly, R/NIR and blue light enhanced osteogenic events in MSCs when cultured in mineralising-inductive media, containing dexamethasone, ascorbic acid, and betaglycerophosphate. No irradiation conditions were reportedly able to stimulate differentiation in cultures maintained in unsupplemented media. Notably, R/NIR was able to stimulate MSC proliferation in mineralising-inductive media, while blue light could inhibit proliferation irrespective of the MSC culture media used. These findings highlight potential differences in the mode of action between R/NIR and blue light, and indicate the need for a conducive environment to enable PBM effects, i.e., the presence of supportive culture conditions.

Data summarised here support PBM of MSC mineralisation events as conforming with the Arndt-Schulz law, with relatively low radiant exposure enhancing cell fate determination, while much higher levels are inhibitory of both proliferation and differentiation. The inhibitory effects of higher radiant exposure of light potentially occur due to either the direct interference of photons on chromophore function, or indirectly due to excessive ROS production [76] or hyperthermia [71, 72]. R/NIR light stimulates the mineralisation potential of MSCs via stimulation of cAMP, respiratory chain signalling, and ROS production. Blue light 
enhanced mineralisation primarily through relatively small increases in ROS levels; however, the precise involvement of the CRY protein in light absorption and subsequent redox signalling still remains to be entirely elucidated [77-79]. To ensure the safety of PBM, thorough characterisation of light irradiation parameters and the further investigations are required for the use of blue and NIR lasers at high radiant exposure. The combined application of PBM and MSCs could offer a prospective modality for hard tissue regenerative medicine in the future provided that the underlying pathways of light-cellular interactions are fully understood, and irradiation parameters are standardised. The light parameters applied should be optimised for delivery, taking into account the absorption of the light within the target tissue while maintaining the safety of host tissues.

\section{Declarations}

Conflict of interest On behalf of all authors, the corresponding author states that there is no conflict of interest.

Open Access This article is licensed under a Creative Commons Attribution 4.0 International License, which permits use, sharing, adaptation, distribution and reproduction in any medium or format, as long as you give appropriate credit to the original author(s) and the source, provide a link to the Creative Commons licence, and indicate if changes were made. The images or other third party material in this article are included in the article's Creative Commons licence, unless indicated otherwise in a credit line to the material. If material is not included in the article's Creative Commons licence and your intended use is not permitted by statutory regulation or exceeds the permitted use, you will need to obtain permission directly from the copyright holder. To view a copy of this licence, visit http://creativecommons.org/licenses/by/4.0/.

\section{References}

1. Zhang, K., Wang, S., Zhou, C., Cheng, L., Gao, X., Xie, X., Sun, J., Wang, H., Weir, M. D., Reynolds, M. A., Zhang, N., Bai, Y., \& $\mathrm{Xu}$, H. H. K. (2018). Advanced smart biomaterials and constructs for hard tissue engineering and regeneration. Bone Research., 6, 31. https://doi.org/10.1038/s41413-018-0032-9

2. Schmidt-Bleek, K., Marcucio, R., \& Duda, G. (2016). Future treatment strategies for delayed bone healing: An osteoimmunologic approach. Journal of the American Academy of Orthopaedic Surgeons, 24(10), e134-e135. https://doi.org/10.5435/ JAAOS-D-16-00513

3. Frencken, J. E., Sharma, P., Stenhouse, L., Green, D., Laverty, D., \& Dietrich, T. (2017). Global epidemiology of dental caries and severe periodontitis-A comprehensive review. Journal of Clinical Periodontology, 44(Suppl 18), S94-S105. https://doi.org/10. $1111 /$ jcpe. 12677

4. Hass, R., Kasper, C., Böhm, S., \& Jacobs, R. (2011). Different populations and sources of human mesenchymal stem cells (MSC): A comparison of adult and neonatal tissue-derived MSC. Cell Communication and Signaling, 9, 12. https://doi.org/10.1186/ 1478-811X-9-12

5. Song, M., Lee, J. H., Bae, J., Bu, Y., \& Kim, E. C. (2017). Human dental pulp stem cells are more effective than human bone marrow-derived mesenchymal stem cells in cerebral ischemic injury. Cell Transplantation, 26(6), 1001-1016. https://doi.org/ 10.3727/096368916X694391

6. Couble, M. L., Farges, J. C., Bleicher, F., Perrat-Mabillon, B., Boudeulle, M., \& Magloire, H. (2000). Odontoblast differentiation of human dental pulp cells in explant cultures. Calcified Tissue International, 66(2), 129-138. https://doi.org/10.1007/PL000 05833

7. Park, K. S., Kim, Y. S., Kim, J. H., Choi, B., Kim, S. H., Tan, A. H. K., Lee, M. S., Lee, M. K., Kwon, C. H., Joh, J. W., Kim, S. J., \& Kim, K. W. (2010). Trophic molecules derived from human mesenchymal stem cells enhance survival, function, and angiogenesis of isolated islets after transplantation. Transplantation, 89(5), 509-517. https://doi.org/10.1097/TP.0b013e3181c7dc99

8. Caplan, A. I., \& Dennis, J. E. (2006). Mesenchymal stem cells as trophic mediators. Journal of Cellular Biochemistry, 98(5), 1076-1084. https://doi.org/10.1002/jcb.20886

9. Huang, Y. Y., Sharma, S. K., Carroll, J., \& Hamblin, M. R. (2011). Biphasic dose response in low level light therapy-An update. Dose Response, 9(4), 602-618. https://doi.org/10.2203/dose-respo nse.11-009.Hamblin

10. Kim, H. B., Baik, K. Y., Seonwoo, H., Jang, K. J., Lee, M. C., Choung, P. H., \& Chung, J. H. (2018). Effects of pulsing of light on the dentinogenesis of dental pulp stem cells in vitro. Science and Reports, 8(1), 2057. https://doi.org/10.1038/ s41598-018-19395-x

11. Sommer, A. P., Pinheiro, A. L., Mester, A. R., Franke, R. P., \& Whelan, H. T. (2001). Biostimulatory windows in low-intensity laser activation: Lasers, scanners, and NASA's light-emitting diode array system. Journal of Clinical Laser Medicine \& Surgery, 19(1), 29-33. https://doi.org/10.1089/104454701750066910

12. de Freitas, L. F., \& Hamblin, M. R. (2016). Proposed mechanisms of photobiomodulation or low-level light therapy. IEEE Journal of Selected Topics in Quantum Electronics, 22(3), 7000417. https:// doi.org/10.1109/JSTQE.2016.2561201

13. Lanzafame, R. J., Stadler, I., Kurtz, A. F., Connelly, R., Peter, T. A., Sr., Brondon, P., \& Olson, D. (2007). Reciprocity of exposure time and irradiance on energy density during photoradiation on wound healing in a murine pressure ulcer model. Lasers in Surgery and Medicine, 39(6), 534-542. https://doi.org/10.1002/1sm. 20519

14. Hamblin, M. R., \& Demidova, T. N. (2006). Mechanisms of low level light therapy. Proceedings of SPIE, 6140, 614001. https:// doi.org/10.1117/12.646294

15. Ginani, F. F., Soares, D. M., Barreto, M. P. E. V., \& Barboza, C. A. G. (2015). Effect of low-level laser therapy on mesenchymal stem cell proliferation: a systematic review. Lasers in Medical Science, 30(8), 2189-2194. https://doi.org/10.1007/s10103-015-1730-9

16. Borzabadi-Farahani, A. (2016). Effect of low-level laser irradiation on proliferation of human dental mesenchymal stem cells; a systemic review. Journal of Photochemistry and Photobiology B: Biology, 162, 577-582. https://doi.org/10.1016/j.jphotobiol.2016. 07.022

17. Li, W. T., Leu, Y. C., \& Wu, J. L. (2010). Red-light light-emitting diode irradiation increases the proliferation and osteogenic differentiation of rat bone marrow mesenchymal stem cells. Photomedicine and Laser Surgery, Suppl, 1, S157-S165. https://doi. org/10.1089/pho.2009.2540

18. Peng, F., Wu, H., Zheng, Y., Xu, X., \& Yu, J. (2012). The effect of noncoherent red light irradiation on proliferation and osteogenic differentiation of bone marrow mesenchymal stem cells. Lasers in Medical Science, 27(3), 645-653. https://doi.org/10.1007/ s10103-011-1005-Z

19. Wu, J. Y., Wang, Y. H., Wang, G. J., Ho, M. L., Wang, C. Z., Yeh, M. L., \& Chen, C. H. (2012). Low-power GaAlAs laser irradiation promotes the proliferation and osteogenic differentiation of stem 
cells via IGF1 and BMP2. PLoS ONE, 7(9), e44027. https://doi. org/10.1371/journal.pone.0044027

20. Wu, J. Y., Chen, C. H., Yeh, L. Y., Yeh, M. L., Ting, C. C., \& Wang, Y. H. (2013). Low-power laser irradiation promotes the proliferation and osteogenic differentiation of human periodontal ligament cells via cyclic adenosine monophosphate. International Journal of Oral Science, 5(2), 85-91. https://doi.org/10.1038/ijos. 2013.38

21. Soleimani, M., Abbasnia, E., Fathi, M., Sahraei, H., Fathi, Y., \& Kaka, G. (2012). The effects of low-level laser irradiation on differentiation and proliferation of human bone marrow mesenchymal stem cells into neurons and osteoblasts-an in vitro study. Lasers in Medical Science, 27(2), 423-430. https://doi.org/10. 1007/s10103-011-0930-1

22. Ateş, G. B., Ak, A., Garipcan, B., \& Gülsoy, M. (2020). Photobiomodulation effects on osteogenic differentiation of adiposederived stem cells. Cytotechnology, 72, 247-258. https://doi.org/ 10.1007/s10616-020-00374-y

23. Kushibiki, T., \& Awazu, K. (2008). Controlling osteogenesis and adipogenesis of mesenchymal stromal cells by regulating a circadian clock protein with laser irradiation. International Journal of Medical Sciences, 5(6), 319-326. https://doi.org/10.7150/ijms.5. 319

24. Kushibiki, T., \& Awazu, K. (2009). Blue laser irradiation enhances extracellular calcification of primary mesenchymal stem cells. Photomedicine and Laser Surgery, 27(3), 493-498. https://doi. org/10.1089/pho.2008.2343

25. Wang, Y., Huan, Y. Y., Wang, Y., Lyu, P., \& Hamblin, M. R. (2016). Photobiomodulation (blue and green light) encourages osteoblastic-differentiation of human adipose-derived stem cells: Role of intracellular calcium and light-gated ion channels. Scientific Reports, 6, 33719. https://doi.org/10.1038/srep33719

26. Zhu, T., Wu, Y., Zhou, X., Yang, Y., \& Wang, Y. (2019). Irradiation by blue light-emitting diode enhances osteogenic differentiation in gingival mesenchymal stem cells in vitro. Lasers in Medical Science, 34, 1473-1481. https://doi.org/10.1007/ s10103-019-02750-3

27. Yang, Y., Zhu, T., Wu, Y., Shu, C., Chen, Q., Yang, J., Luo, X., \& Wang, Y. (2020). Irradiation with blue light-emitting diode enhances osteogenic differentiation of stem cells from the apical papilla. Lasers in Medical Science, 35, 1981-1988. https://doi. org/10.1007/s10103-020-02995-3

28. Karu, T. I., \& Kolyakov, S. F. (2005). Exact action spectra for cellular responses relevant to phototherapy. Photomedicine and Laser Surgery, 23(4), 355-361. https://doi.org/10.1089/pho.2005. 23.355

29. Eichler, M., Lavi, R., Shainberg, A., \& Lubart, R. (2005). Flavins are source of visible-light-induced free radical formation in cells. Lasers in Surgery and Medicine, 37(4), 314-319. https://doi.org/ 10.1002/lsm.20239

30. Lubart, R., Lavi, R., Friedmann, H., \& Rochkind, S. (2006). Photochemistry and photobiology of light absorption by living cells. Photomedicine and Laser Surgery, 24(2), 179-185. https://doi. org/10.1089/pho.2006.24.179

31. Farivar, S., Malekshahabi, T., \& Shiari, R. (2014). Biological effects of low level laser therapy. Journal of Lasers in Medical Sciences, 5(2), 58-62. https://doi.org/10.22037/2010.v5i2.5540

32. Chen, C. T., Shih, Y. R. V., Kuo, T. K., Lee, O. K., \& Wei, Y. H. (2008). Coordinated changes of mitochondrial biogenesis and antioxidant enzymes during osteogenic differentiation of human mesenchymal stem cells. Stem Cells, 26(4), 960-968. https://doi. org/10.1634/stemcells.2007-0509

33. Lyublinskaya, O. G., Borisov, Y. G., Pugovkina, N. A., Smirnova, I. S., Obidina, J. V., Ivanova, J. S., Zenin, V. V., Shatrova, A. N., Borodkina, A. V., Aksenov, N. D., Zemelko, V. I., Burova, E. B., Puzanov, M. V., \& Nikolsky, N. N. (2015). Reactive oxygen species are required for human mesenchymal stem cells to initiate proliferation after the quiescence exit. Oxidative Medicine and Cellular Longevity. https://doi.org/10.1155/2015/502105

34. Karu, T. (1987). Photobiological fundamentals of low-power laser therapy. IEEE Journal of Quantum Electronics, 23(10), 17031717. https://doi.org/10.1109/JQE.1987.1073236

35. Karu, T. (1999). Primary and secondary mechanisms of action of visible to near-IR radiation on cells. Journal of Photochemistry and Photobiology B: Biology, 49(1), 1-17. https://doi.org/10. 1016/S1011-1344(98)00219-X

36. Karu, T. I., Kalendo, G. S., Letokhov, V. S., \& Lobko, V. V. (1982). Biostimulation of Hela cells by low-intensity visible light. Il Nuovo Cimento D, 1(6), 828-840. https://doi.org/10.1007/ BF02457460

37. Karu, T. I., Pyatibrat, L. V., \& Afanasyeva, N. I. (2005). Cellular effects of low power laser therapy can be mediated by nitric oxid. Lasers in Surgery and Medicine, 36(4), 307-314. https:// doi.org/10.1002/lsm.20148

38. Antunes, F., Boveris, A., \& Cadenas, E. (2004). On the mechanism and biology of cytochrome oxidase inhibition by nitric oxide. Proceedings of the National Academy of Sciences of the United States of America, 101(48), 16774-16779. https://doi. org/10.1073/pnas.0405368101

39. Lane, N. (2006). Cell biology: Power games. Nature, 443(7114), 901-903. https://doi.org/10.1038/443901a

40. Wong-Riley, M. T. T., Liang, H. L., Eells, J. T., Chance, B., Henry, M. M., Buchmann, E., Kane, M., \& Whelan, H. T. (2005). Photobiomodulation directly benefits primary neurons functionally inactivated by toxins: Role of cytochrome c oxidase. Journal of Biological Chemistry, 280(6), 4761-4771. https://doi.org/10.1074/jbc.M409650200

41. Lubart, R., Wollman, Y., Friedmann, H., Rochkind, S., \& Laulicht, S. (1992). Effects of visible and near-infrared lasers on cell cultures. Journal of Photochemistry and Photobiology, B: Biology, 12(3), 305-310. https://doi.org/10.1016/1011-1344(92) 85032-P

42. Lavi, R., Shainberg, A., Shneyvays, V., Hochauser, E., AIsaac, A., Zinman, T., Friedmann, H., \& Lubart, R. (2002). Detailed analysis of reactive oxygen species induced by visible light in various cell type. Lasers in Surgery and Medicine, 42(6), 473-480. https://doi. org/10.1002/1sm.20919

43. Finkel, T. (2003). Oxidant signals and oxidative stress. Current Opinion in Cell Biology, 15(2), 247-254. https://doi.org/10.1016/ S0955-0674(03)00002-4

44. Janssen-Heininger, Y. M. W., Mossman, B. T., Heintz, N. H., Forman, H. J., Kalyanaraman, B., Finkel, T., Stamler, J. S., Rhee, S. G., \& van der Vliet, A. (2008). Redox-based regulation of signal transduction: Principles, pitfalls, and promises. Free Radical Biology and Medicine, 45(1), 1-17. https://doi.org/10.1016/j.freer adbiomed.2008.03.011

45. Hsu, D. S., Zhao, X., Zhao, S., Kazantsev, A., Wang, R. P., Todo, T., Wei, Y. F., \& Sancar, A. (1996). Putative human blue-light photoreceptors hCRY1 and hCRY2 are flavoproteins. Biochemistry, 35(44), 13871-21387. https://doi.org/10.1021/bi962209o

46. Lin, C., Robertson, D. E., Ahmad, M., Raibekas, A. A., Jorns, M. S., Dutton, P. L., \& Cashmor, A. R. (1995). Association of flavin adenine dinucleotide with the Arabidopsis blue light receptor CRY1. Science, 269(5226), 968-970. https://doi.org/10.1126/ science. 7638620

47. Todo, T., Kim, S. T., Hitomi, K., Otoshi, E., Inui, T., Morioka, H., Kobayashi, H., Ohtsuka, E., Toh, H., \& Ikenaga, M. (1997). Flavin adenine dinucleotide as a chromophore of the Xenopus (6-4)photolyase. Nucleic Acids Research, 25(4), 764-768. https:// doi.org/10.1093/nar/25.4.764

48. Shearman, L. P., Sriram, S., Weaver, D. R., Maywood, E. S., Chaves, I., Zheng, B., Kume, K., Lee, C. C., Gvan der Horst, G. 
T., Hastings, M. H., \& Reppert, S. M. (2000). Interacting molecular loops in the mammalian circadian clock. Science, 288(5468), 1013-1019. https://doi.org/10.1126/science.288.5468.1013

49. Tamaru, T., Hattori, M., Ninomiya, Y., Kawamura, G., Varès, G., Honda, K., Mishra, D. P., Wang, B., Benjamin, I., Sassone-Corsi, P., Ozawa, T., \& Takamatsu, K. (2013). ROS stress resets circadian clocks to coordinate pro-survival signals. PLOS ONE, 8(12), e82006. https://doi.org/10.1371/journal.pone.0082006

50. Fu, L., Patel, M. S., Bradley, A., Wagner, E. F., \& Karsenty, G. (2005). The molecular clock mediates leptin-regulated bone formation. Cell, 122(5), 803-815. https://doi.org/10.1016/j.cell.2005. 06.028

51. Griendling, K., Sorescu, D., \& Ushio-Fukai, M. (2000). NAD(P)H oxidase: Role in cardiovascular biology and disease. Circulation Research, 86(5), 494-501. https://doi.org/10.1161/01.RES.86.5. 494

52. Braunersreuther, V., \& Jaquet, V. (2012). Reactive oxygen species in myocardial reperfusion injury: From physiopathology to therapeutic approaches. Current Pharmaceutical Biotechnology, 13(1), 97-114. https://doi.org/10.2174/138920112798868782

53. Starkov, A. A. (2008). The role of mitochondria in reactive oxygen species metabolism and signalling. Annals of the New York Academy of Sciences, 1147, 37-52. https://doi.org/10.1196/annals. 1427.015

54. Kukreja, R. C., Kontos, H. A., Hess, M. L., \& Ellis, E. F. (1986). PGH synthase and lipoxygenase generate superoxide in the presence of NADH or NADPH. Circulation Research, 59(6), 612-619. https://doi.org/10.1161/01.RES.59.6.612

55. Roy, P., Roy, S. K., Mitra, A., \& Kulkarni, A. P. (1994). Superoxide generation by lipoxygenase in the presence of NADH and NADPH. Biochimica et Biophysica Acta, 1214(2), 171-179. https://doi.org/10.1016/0005-2760(94)90041-8

56. O’Donnell, V. B., \& Azzi, A. (1996). High rates of extracellular superoxide generation by cultured human fibroblasts: Involvement of a lipid-metabolizing enzyme. Biochemical Journal, 318(Pt 3), 805-812. https://doi.org/10.1042/bj3180805

57. Nathan, C., \& Cunningham-Bussel, A. (2013). Beyond oxidative stress: An immunologist's guide to reactive oxygen species. Nature Reviews Immunology, 13(5), 349-361. https://doi.org/10. 1038/nri3423

58. Gross, E., Sevier, C. S., Heldman, N., Vitu, E., Bentzur, M., Kaiser, C. A., Thorpe, C., \& Fass, D. (2006). Generating disulfides enzymatically: Reaction products and electron acceptors of the endoplasmic reticulum thiol oxidase Ero1p. Proceedings of the National Academy of Sciences of the United States of America, 103(2), 299-304. https://doi.org/10.1073/pnas.0506448103

59. Wu, R. F., Ma, Z., Liu, Z. L. S., \& Terada, L. S. (2010). Nox4derived $\mathrm{H} 2 \mathrm{O} 2$ mediates endoplasmic reticulum signaling through local Ras activation. Molecular and Cellular Biology, 30(14), 3553-3568. https://doi.org/10.1128/mcb.01445-09

60. Boveris, A., Oshino, N., \& Chance, B. (1972). The cellular production of hydrogen peroxide. The Biochemical Journal, 128(3), 617-630. https://doi.org/10.1042/bj1280617

61. Matsui, S., Takahashi, C., Tsujimoto, Y., \& Matsushima, K. (2009). Stimulatory effects of low-concentration reactive oxygen species on calcification ability of human dental pulp cells. Journal of Endodontics, 35(1), 67-72. https://doi.org/10.1016/j.joen.2008. 08.034

62. Tao, J., Wang, H., Zhai, Y., Park, H., Wang, J., Ji, F., \& Zhang, Z. (2016). Downregulation of Nrf2 promotes autophagy-dependent osteoblastic differentiation of adipose-derived mesenchymal stem cells. Experimental Cell Research, 349(2), 221-229. https://doi. org/10.1016/j.yexcr.2016.09.013

63. Bigarella, C. L., Liang, R., \& Ghaffari, S. (2014). Stem cells and the impact of ROS signalling. Development (Cambridge), 22, 4206-4218. https://doi.org/10.1242/dev.107086
64. Valle-Prieto, A., \& Conget, P. A. (2010). Human mesenchymal stem cells efficiently manage oxidative stress. Stem Cells and Development, 19(12), 1885-1893. https://doi.org/10.1089/scd. 2010.0093

65. Kim, K. S., Choi, H. W., Yoon, H. E., \& Kim, I. Y. (2010). Reactive oxygen species generated by NADPH oxidase 2 and 4 are required for chondrogenic differentiation. Journal of Biological Chemistry, 285(51), 40294-40302. https://doi.org/10.1074/jbc. M110.126821

66. Atashi, F., Modarressi, A., \& Pepper, M. S. (2015). The role of reactive oxygen species in mesenchymal stem cell adipogenic and osteogenic differentiation: A review. Stem Cells and Development, 24(10), 1150-1163. https://doi.org/10.1089/scd.2014.0484

67. Denu, R. A., \& Hematti, P. (2016). Effects of oxidative stress on mesenchymal stem cell biology. Oxidative Medicine and Cellular Longevity. https://doi.org/10.1155/2016/2989076

68. Amaroli, A., Agas, D., Laus, F., Cuteri, V., Hanna, R., Sabbieti, M. G., \& Benedicenti, S. (2018). The effects of photobiomodulation of $808 \mathrm{~nm}$ diode laser therapy at higher fluence on the in vitro osteogenic differentiation of bone marrow stromal cells. Frontiers in Physiology, 9, 123. https://doi.org/10.3389/fphys.2018.00123

69. Turrioni, A. P. S., Basso, F. G., Montoro, L. A., De Almeida, L. D. F. D., Costa, C. A. D. S., \& Hebling, J. (2014). Phototherapy up-regulates dentin matrix proteins expression and synthesis by stem cells from human-exfoliated deciduous teeth. Journal of Dentistry, 42(10), 1292-1299. https://doi.org/10.1016/j.jdent. 2014.07.014

70. Yuan, Y., Yan, G., Gong, R., Zhang, L., Liu, T., Feng, C., Du, W., Wang, Y., Yang, F., Li, Y., Guo, S., Ding, F., Ma, W., Idiiatullina, E., Pavlov, V., Han, Z., Cai, B., \& Yang, L. (2017). Effects of blue light emitting diode irradiation on the proliferation, apoptosis and differentiation of bone marrow-derived mesenchymal stem cells. Cellular Physiology and Biochemistry, 43(1), 237-246. https:// doi.org/10.1159/000480344

71. Glavaš, H., Vukobratović, M., \& Keser, T. (2018). Infrared thermography as control of handheld IPL device for home-use. Journal of Cosmetic and Laser Therapy, 20(5), 269-277. https://doi. org/10.1080/14764172.2017.1406607

72. Wang, Z., Cai, F., Chen, X., Luo, M., Hu, L., \& Lu, Y. (2013). The role of mitochondria-derived reactive oxygen species in hyperthermia-induced platelet apoptosis. PLoS ONE, 8(9), e75044. https://doi.org/10.1371/journal.pone.0075044

73. Shui, C., \& Scutt, A. (2001). Mild heat shock induces proliferation, alkaline phosphatase activity, and mineralization in human bone marrow stromal cells and Mg-63 cells in vitro. Journal of Bone and Mineral Research, 16(4), 731-741. https://doi.org/10. 1359/jbmr.2001.16.4.731

74. Chen, J., Shi, Z. D., Ji, X., Morales, J., Zhang, J., Kaur, N., \& Wang, S. (2013). Enhanced osteogenesis of human mesenchymal stem cells by periodic heat shock in self-assembling peptide hydrogel. Tissue Engineering Part A, 19(5-6), 716-728. https:// doi.org/10.1089/ten.tea.2012.0070

75. Li, C., Sunderic, K., Nicoll, S. B., \& Wang, S. (2018). Downregulation of Heat Shock Protein 70 Impairs Osteogenic and Chondrogenic Differentiation in Human Mesenchymal Stem Cells. Science and Reports, 8, 553. https://doi.org/10.1038/s41598-017-18541-1

76. Sommer, A. P. (2019). Mitochondrial cytochrome c oxidase is not the primary acceptor for near infrared light-It is mitochondrial bound water: the principles of low-level light therapy. Annals of Translational Medicine, 7(Suppl 1), S13. https://doi.org/10.21037/ atm.2019.01.43

77. Arai, M., Shibata, Y., Pugdee, K., Abiko, Y., \& Ogat, Y. (2007). Effects of reactive oxygen species (ROS) on antioxidant system and osteoblastic differentiation in MC3T3-E1 cells. IUBMB Life, 59(1), 27-33. https://doi.org/10.1080/15216540601156188 
78. Consentino, L., Lambert, S., Martino, C., Jourdan, N., Bouchet, P. E., Witczak, J., Castella, P., El-Esawi, M., Corbineau, F., d'Harlingue, A., \& Ahmad, M. (2015). Blue-light dependent reactive oxygen species formation by Arabidopsis cryptochrome may define a novel evolutionarily conserved signaling mechanis. New Phytologist, 206(4), 1450-1462. https://doi.org/10.1111/nph. 13341
79. Jourdan, N., Martino, C. F., El-Esawi, M., Witczak, J., Bouchet, P. E., d'Harlingue, A., \& Ahmad, M. (2015). Blue-light dependent ros formation by arabidopsis cryptochrome-2 may contribute toward its signaling role. Plant Signaling and Behavior, 10(8), e1042647. https://doi.org/10.1080/15592324.2015.1042647 